\title{
Eğitmenlerin Bakış Açısıyla Pilatese Yönelme Sebepleri ve Alandaki Sorunlara Ait Görüşler
}

\author{
Nuri Berk GÜNGÖR ${ }^{* 1}$, Oğuz Kaan ESENTÜRK²
}

${ }^{1}$ Karamanoğlu Mehmetbey Üniversitesi, Beden Eğitimi ve Spor Yüksekokulu. https://orcid.org/0000-0002-6579-9146

${ }^{2}$ Erzincan Binali Yıldırım Üniversitesi, Eğitim Fakültesi. https://orcid.org/ 0000-0002-0566-838X

Orijinal Makale

Gönderi Tarihi: 21.04.2020
Kabul Tarihi: 07.06.2020
DOI: $10.30769 /$ usbd.725038

Online Yayın Tarihi: 30.06 .2020

$\ddot{O} z$

$\mathrm{Bu}$ araştırmanın amacı, pilates eğitmenlerinin bakış açısıyla pilatese yönelme sebepleri ve alandaki sorunlar ile ilgili düşüncelerini ortaya koymaktır. Araştırmanın çalı̧̧ma grubunu, 2019 yılında Muğla'da özel sektörde çalışan 10 pilates eğitmeni oluşturmaktadır. Verilerin toplanması aşamasında uzman kişiler tarafından hazırlanmış yarı yapılandırılmış görüşme formu kullanılmıştır. Görüşme formu eğitmenlere yöneltilmek üzere hazırlanan toplamda 10 yarı yapılandırılmış sorudan oluşmaktadır. Görüşmeler randevu alınarak, gürültüden arındırılmış bir ortamda ses kayıt cihazı ile gerçekleştirilmiştir. Sonrasında görüşme kayıtları bilgisayar ortamında yazılı metinlere çevrilerek analizler yapılmıştır. Verilerin analizinde betimsel ve içerik analizi teknikleri kullanılmıştır. Araştırmanın güvenirliğine katkı sağlamak için katılımcıların yarı yapılandırılmı̣s görüşme formunda yer alan sorulara vermiş oldukları cevaplar doğrudan alıntılar ile verilmiş olup, Miles \& Huberman'ın (1994) formülü (=görüş birliği / (görüş birliği+görüş ayrılığı) kullanılmıştır. Gerçekleştirilen analizler sonucunda; pilatese yönelme sebepleri ve alandaki sorunlara ilişkin görüşleri kategoriler aracılığı ile ifade edilmiştir. Sonuç olarak; pilatese yönelme sebepleri arasında, sosyal medya paylaşımların, belirli bir popülariteye sahip olmasının, kilo kontrolünü sağlama, vücut şekillendirmeye katkısı oluşunun, bel ve boyun ağrılarına iyi gelmesinin, kendini iyi hissetme ve ruhsal doyum sağlamasının, çevre yönlendirmesinin olduğu belirlenmiştir. Buna ek olarak; profesyonel anlamda ise maddi getirisinin önemli bir etki unsuru olduğu ifade edilebilir. Katılımcıların en önemli sorun olarak belirttikleri unsurlar ise antrenör niteliği ve stüdyo sayısındaki fazlalık olmuştur.

Anahtar kelimeler: Pilates, eğitmen, spor, nitel araştırma.

\section{The Reasons of The Instructors for The Pilates and Their Points of The Problems}

\begin{abstract}
The aim of this research is to reveal the opinions of pilates instructors about the reasons for turning to pilates and problems in the field. The study group of the research consists of 10 pilates instructors working in the private sector in Muğla in 2019. A semi-structured interview form prepared by experts was used during the data collection phase. The interview form consists of 10 semi-structured questions prepared to be directed to the trainers. The interviews were made by appointment and in a noisefree environment with a voice recorder. Later, the interviews were translated into written texts in the computer environment and analyzes were made. Descriptive and content analysis techniques were used to analyze the data. In order to contribute to the reliability of the research, the answers given by the participants to the questions in the semi-structured interview form were given with direct quotations and Miles and Huberman's (1994) formula (= consensus / (consensus + divergence)) was used. As a result of the analyzes carried out; Reasons for turning to pilates and their views on the problems in the field were expressed through categories. As a result; Among the reasons for turning to pilates, it is determined that social media sharing has a certain popularity, contributes to weight control, contributes to body shaping, improves waist and neck pains, feels well and provides mental satisfaction and environmental orientation. In addition; In a professional sense, it can be stated that the material return is an important factor. The factors that the participants stated as the most important problem were the quality of their coaches and the number of studios.
\end{abstract}

Keywords: Pilates, trainer, sports, qualitative research.

\footnotetext{
* Sorumlu Yazar: Nuri Berk Güngör, E-Posta: nuriberkgungor@ gmail.com
} 


\section{GíRiş}

Kaliteli bir yaşamın en önemli koşulu şüphesiz ki sağlıklı olma durumudur. Teknolojik ürünlerin gün geçtikçe hayatımızdaki sayısının artması bazı hususlarda bize dezavantaj sağlamaktadır. Bu ürünler her ne kadar bize katkı sağlasa da inaktif birey sayısının artması sonucunu da beraberinde getirmektedir. Hareketsiz yaşam, modern toplumların karşısındaki ciddi bir tehlikeyi işaret etmektedir (Bozkuş, Türkmen, Kul, Özkan, Öz ve Cengiz, 2013). Hareketsiz yaşamın oluşturabileceği sorunların çözümünde en etkili yöntemlerden birisi fiziksel aktivitedir. Ancak, son yıllarda bireylerin fiziksel aktivite düzeyinin çalışma koşullarından kaynaklı olarak düştügü gözlemlenmiştir (Bassett, Schneider \& Hntington, 2004; Boyce, Boone, Cioci \& Lee, 2008; Egger, Vogels \& Westerterp, 2001). Bu durumda sağlık sorunlarının artmasında rol oynamaktadır (Satcher \& Lee, 1996).

Modernleşme ve endüstrileşmenin bireylerde hareket eksikliğinden kaynaklı problemleri ortaya çıkarması ile fiziksel aktivite bir çözüm olarak kendisine yer bulmuştur. Fiziksel aktivite düzeyi ile yaşam kalitesi arasındaki ilişki, üzerinde durulan bir konu haline gelerek bir çalışma alanı oluşturmuştur. Bireylerin fiziksel aktivite düzeyi son yıllarda düşme eğilimindeyken gerek ulaşılabilirliğinin kolay oluşu gerekse de araç ve mekân durumdan bağımsız olarak gerçekleştirilebiliyor oluşu pilatesin popülerliğini arttırmıştır.

Pilates metodu; Joseph Hubertus Pilates tarafindan geliştiren, New York'ta egzersiz stüdyosunu açmasıyla birlikte temelleri atılan ve zamanla değişiklikler göstererek günümüzdeki formuna kavuşan bir metoddur (Bryan \& Hawson, 2003; Di Lorenzo, 2011; Metel, Milert \& Szcygiel, 2012). Pilates, yayılmaya başladığında genellikle dansçılar tarafından tercih edilen bir durumdayken, faydalarının görülmesi ile birlikte zamanla sağlık amaçlı temel bir egzersiz olarak tercih edilmeye başlanmıştır (Kalkan, 2019; Ünal ve Dizmek, 2014). Bununla beraber postür bozuklukları ve ağrılardan kaynaklı sorunların giderilmesinde de hekimler tarafından önerilen bir tedavi aracı rolü edinmiştir (Anderson \& Spector, 2000; Wellsi Kolt \& Bialocerkowski, 2012).

Pilatesin her yaş grubuna uygun, hareketlerinin kolay ve güvenli bir yapıda olması yayılma alanını genişletmiştir. Son yıllarda artan fitness merkezlerinde daha profesyonel bir görünüm kazanmasıyla birçok kişinin farkında olduğu bir egzersiz türü haline gelmiş ve gün geçtikçe pilatese ilgi duyarak başlayan bireylerin sayısında artış gözlenmiştir. Bununla beraber, pilatesin kazanımlarının elde edilebilmesi için öğretici rolünde olan eğitmenler de önem taşımaktadır. Bu mesleği hangi amaçla icra ettikleri ve nitelikleri kaliteyi etkileyen unsurlar arasındadır. Literatür incelendiğinde; pilates ile ilgili çalışmaların çeşitliliği bilişsel, psikolojik ve fizyolojik etkenler çerçevesinde oluşmuştur (Cabbaroğlu, 2019; Göz, 2020; Jago, Jonker, Missaghian \& Baranowski, 2006; Kayaoğlu, 2019; Keskin, 2018; Kloubec, 2010; Segal, Hein \& Basford, 2004). Ancak, pilates eğitmenlerinin bakış açısıyla branşa başlama sebepleri ve alanda bulunan sorunları inceleyen bir araştırmaya rastlanmamıştır. Dolayısıyla bu araştırmada, pilates eğitmenlerinin bakış açısıyla branşa başlama sebeplerinin incelenmesi ve alana ait sorunların belirlenmesi amaçlanmıştır. İlgili literatür göz önünde bulundurulduğunda bu araştırma; pilates eğitmenlerinin görüşlerini yansıtması ve alanda yaşanan sorunların belirlenmesine katkı sağlaması sebebi ile önem taşımaktadır. 


\section{YÖNTEM}

\section{Araştırma Modeli}

Araştırmada nitel araştırma yaklaşımlarından temel nitel araştırma modeli kullanılmıştır. Merriam \& Tisdell (2015) temel nitel araştırma modelini, araştırmacıların bireylerin yaşamdaki deneyimlerini nasıl yorumladıklarını, ne tür duygulara sahip olduklarını, dünyayı nasıl algıladıklarını ve şekillendirdiklerini araştıran bir yöntem olarak tanımlamıştır.

\section{Çalışma Grubu}

Araştırmanın çalışma grubunu, 2019 yılında Muğla ilinde özel kuruluşlarda çalışmakta olan 3’ü erkek, 7'si kadın olmak üzere toplam 10 pilates eğitmeni oluşturmaktadır. Çalışma grubu belirlenirken amaçlı örnekleme yöntemi kullanılmıştır. $\mathrm{Bu}$ yöntem araştırmanın amacı doğrultusunda önceden belirlenmiş ölçütlere göre katılımcı seçimine olanak sağlamıştır (Yıldırım ve Şimşek, 2016). Çalışma grubunu oluşturan katılımcıların, en az 1. kademe pilates yardımcı antrenörlük belgesine sahip olması amaçlanmıştır. Bu amaç, sektörde en az 1 yıl çalışma tecrübesi koşulunun da sağlanmasına katkı sağlamıştır. Çalışma grubuna ilişkin demografik bilgiler aşağıdaki tabloda verilmiştir.

Tablo 1. Katılımcıların demografik özellikleri

\begin{tabular}{ccccc}
\hline Katılımcılar & Cinsiyet & Yaş & Çalışılan İl & Eğitim Düzeyi \\
\hline 1. Katılımcı & Kadın & 27 & Muğla & Üniversite \\
2. Katılımcı & Kadın & 24 & Muğla & Üniversite \\
3. Katılımcı & Kadın & 32 & Muğla & Üniversite \\
4. Katılımcı & Kadın & 27 & Muğla & Üniversite \\
5. Katılımcı & Kadın & 27 & Muğla & Üniversite \\
6. Katılımcı & Kadın & 28 & Muğla & Üniversite \\
7. Katılımcı & Kadın & 24 & Muğla & Üniversite \\
8. Katılımcı & Erkek & 28 & Muğla & Üniversite \\
9. Katılımcı & Erkek & 27 & Muğla & Üniversite \\
10. Katılımcı & Erkek & 30 & Muğla & Üniversite \\
\hline
\end{tabular}

\section{Veri Toplama Aracı}

Veri toplama tekniği olarak önceden belirlenmiş ve ciddi bir amaç için yapılan soru sorma ve cevaplama tarzına dayalı karşılıklı ve etkileşimli bir iletişim süreci olarak nitelendirilen görüşme tekniği kullanılmıştır (Ekiz, 2009). Bu sebeple 10 sorudan oluşan yarı yapılandırılmış görüşme formu oluşturulmuştur. Hazırlanan sorular geçerlik, açıklık ve anlaşılırlık ölçütlerini taşıyabilmeleri amacıyla beden eğitimi ve spor alanında uzman bir kişi, pilates antrenörlük lisansına sahip bir kişi ve Türkçe eğitimi alanında uzman bir kişi olmak üzere toplamda üç uzman görüşüne sunulmuştur. Uzmanlardan gelen dönütler ve düzeltmeler doğrultusunda gerekli düzenlemeler yapılmış ve nihai form oluşturulmuştur. Görüşme katılımcının uygun gördüğü mekân ve zaman diliminde yapılıış ve araştırmacı ile katılımcı arasında bire bir olarak gerçekleştirilmiştir. Elde edilecek verilerin kalitesi açısından 
görüşmenin yapıldığı mekânın ses ve gürültüden arındırılmış olmasına özen gösterilmiştir. Görüşme esnasında ses kayıt cihazı kullanılmıştır. Görüşme başlamadan önce araştırmanın amacı katılımcıya detaylı olarak açıklanmış, istediği zaman görüşmeye ara verebileceği ya da görüşmeyi sonlandırabileceği belirtilmiştir. Sorular araştırmacı tarafından katılımcıya yöneltilmiştir. Görüşmeler, 10 farklı katılımc1 ile yaklaşık $45^{\prime}$ er dakika olarak gerçekleştirilmiştir. Her bir görüşmenin bitimi ile katılımcılara konu ile ilgili ekleme yapmak istediği herhangi bir şey olup olmadığı sorularak, katılımları için teşekkür edilmiştir.

\section{Verilerin Analizi}

Katılımcılar ile görüşmeler tamamlandıktan sonra görüşme kayıtları araştırmacılar tarafından yazılı metin haline dönüştürülmüştür. Sonrasında katılımcılara ait görüşme metinleri her bir katılımcıya ayrı ayrı olmak üzere ekleme ve düzeltme yapmak istedikleri bölümler olabileceği düşünülerek teyide sunulmuştur. Katılımcıların teyidinden sonra verilerin analizi gerçekleştirilmiştir.

Veriler betimsel ve içerik analizi tekniği kullanılarak çözümlenmiştir. Betimsel analiz tekniğinde veriler araştırma sorularının ortaya koyduğu temalara göre düzenlenebileceği gibi, görüşmede yer alan sorular dikkate alınarak da sunulabilir. Betimsel analizde görüşmeye katılanların görüşlerini çarpıcı bir biçimde yansıtmak amacıyla doğrudan alıntılara sık sık yer verilir (Yıldırım ve Şimşek, 2011). İçerik analizi, verilerin tanımlanması, kodlanması ve kategorileştirilmesi sürecidir (Patton, 2014). Elde edilen veriler araştırmacılar tarafından gözden geçirilerek ve kodlar yazılarak kod listesi oluşturulmuştur. Kodlar ise ortak özelliklerine göre bir araya getirilerek kategorilere ulaşılmıştır. İlgili kategorileri temsil eden kodlar birbirleri ile ilişkili biçimde açıklanarak yorumlanmış ve sonuçlar elde edilmiştir. Bununla beraber, elde edilen veriler katılımcı görüşlerine yer vererek tablolaştırılarak bulguların geçerliği sağlanmıştır. Çalışmanın güvenirliğine yönelik uzmanlararası görüş birliği katsayısı hesaplanmıştır. Görüş ayrılığı yaşanılan noktalarda her iki uzman tarafindan tartışılarak uzlaşma sağlanmıştır. Verilerin güvenirliği sağlamak amacıyla Miles \& Huberman'ın (1994) (Görüş birliği/(Görüş birliği + Görüş ayrılığı) x 100) formülü kullanılmıştır. Çalışma sonuçlarının güvenirliği için uzmanlar arası görüş birliği \%90 olarak hesaplanmıştır.

\section{BULGULAR}

Araştırmada katılımcılarla gerçekleştirilen görüşmelerden elde edilen bulgular, araştırma konusu kapsamında ortaya konulmuştur. Pilates eğitmenlerinin bakış açısıyla branşa yönelme sebepleri ve alandaki sorunlara ait görüşlerin incelendiği bu araştırmada, toplanan verilerin analiz edilmesiyle ulaşılan kategoriler, kodlar ve ilgili kodların tekrarlanma sıklığını ifade eden frekans değerleri Tablo 2'de verilmiştir. 
Güngör, N. B., ve Esentürk, O. K. (2020). Eğitmenlerin bakış açısıyla pilatese yönelme sebepleri ve alandaki sorunlara ait görüşler. Ulusal Spor Bilimleri Dergisi, 4(1), 35-49.

Tablo 2. Katılımcıların pilates branşına yönelim ile ilgili düşüncelerine ait kategoriler, kodlar ve frekans değerleri

\begin{tabular}{lcc}
\hline \multicolumn{1}{c}{ Kategoriler } & Kodlar & Frekans \\
\hline Spor Geçmişi f(3) & -Farklı Spor Branşları ile İlgilenmiş Olma & 3 \\
\hline Rekreatif Amaç f(2) & -Hobi Olarak Görme & 2 \\
\hline \multirow{2}{*}{ Toplumsal Sebepler f(9) } & -Popülarite & 3 \\
& -Sosyal Medya Kullanımı & 5 \\
& Kadın Kadına İcra Edilebilmesi & 1 \\
\hline \multirow{2}{*}{ Fiziksel Sağlık f(8) } & -Omurga Ağrıları & 3 \\
& -Bel Ağr1ları & 3 \\
\hline \multirow{2}{*}{ Zihinsel Sağlık f(2) } & -Boyun Ağrıları & 2 \\
\hline \multirow{3}{*}{ Estetik Görünüm f(7) } & -Kendini İyi Hissetme & 1 \\
& -Ruhsal Doyum & 1 \\
\hline \multirow{2}{*}{ Tavsiye f(3) } & -Zayıflama & 3 \\
\hline Kolay Ulaşılabilirlik f(2) & - Sikılaşma & 1 \\
\hline \multirow{2}{*}{ Maddi Beklentiler f(8) } & -Boy Uzatma & 1 \\
& -Vücut Şekillendirme & 2 \\
\hline
\end{tabular}

Tablo 2 incelendiğinde, pilates branşına yönelme sebepleri 9 kategori altında toplanmıştır. Bu kategoriler sırasıyla; "Spor geçmişi", "Rekreatif amaç", "Toplumsal sebepler", Fiziksel sağlık", "Zihinsel sağlık", Estetik görünüm", "Tavsiye", "Kolay ulaşılabilirlik" ve "Maddi beklentiler" başlikları ile ortaya konulmuştur. İlgili kategorilerden toplamda 20 kod elde edilmiştir. Kategoriler dikkate alındığında; Spor geçmişi kategorisinde, Farklı spor branşları ile ilgilenmiş olma kodu; Rekreatif amaç kategorisinde, Hobi olarak görme kodu, Toplumsal sebepler kategorisinde, Popülarite, Sosyal medya kullanımı, kadın kadına icra edilebilme kodları, Fiziksel sağlık kategorisinde, Omurga ağrıları, Bel ağrıları, Boyun ağrıları kodları, Zihinsel sağlık kategorisinde, Kendini iyi hissetme, Ruhsal doyum kodları, Estetik görünüm kategorisinde, Zayıflama, Sıkılaşma, Boy uzatma, Vücut şekillendirme kodları, Tavsiye kategorisinde, Patron yönlendirmesi, komşu yönlendirmesi kodları, Kolay ulaşılabilirlik kategorisinde, Evde gerçekleştirme imkanı kodu, Maddi beklentiler kategorisinde ise, Yüksek maaş imkanı, Mesleki yatırım ve Belge kiralayabilme imkanı kodları yer almıştır.

Tablo 2'de yer alan frekans değerleri incelendiğinde, katılımcıların pilates branşına yönelme sebebi olarak en fazla görüş bildirdikleri kategorinin "Toplumsal sebepler" $f(9)$ olduğu görülmektedir. Bununla beraber Tablo 1 katılımcıların pilates branşına yönelme nedeni olarak en az görüş bildirdikleri kategorilerin ise; Rekreatif amaç, Zihinsel sağlik ve Kolay ulaşılabilirlik olduğunu göstermiştir. Katılımcıların pilates branşına yönelme sebepleri önem derecesine göre siralandığında; "Toplumsal sebepler", "Fiziksel sağlık", "Maddi beklentiler", "Estetik görünüm”, "Spor geçmişi”, "Tavsiye", "Rekreatif amaç", "Zihinsel sağlk" ve "Kolay ulaşılabilirlik" şeklinde belirtilebilir. Bu bölümde pilates branşına yönelten sebepler kategoriler doğrultusunda ayrı ayrı incelenmiş ve kodlara ilişkin katılımcı görüşlerine ait doğrudan alıntılar ile birlikte sunulmuştur. 


\section{Spor Geçmişi Kategorisi}

Katılımcıların spor geçmişi kategori ile ilgili görüşleri farklı spor branşları ile ilgilenmiş olma şeklinde kodlanmıştır. Bu koda ilişskin frekans değerleri incelendiğinde 3 olduğu tespit edilmiştir. Farklı spor branşları ile ilgilenmiş olma koduna yönelik örnek ifadeler aşağıda sunulmuştur.

“...ben 6 yaşında cimnastik ile spora başladım. Birkaç sene devam ettikten sonra okul takımında voleybol oynadım. Aile engelinden dolay bunlar hobi olarak kaldı sadece. Üniversiteyse dansa yöneldim ve zumba ile ilgilendim. Bununla beraber de fitness ilgimi çekti ona başladım. Bu süreci düşündügüumde pilatese olan ilgimin buradan geldiğini düşünüyorum (K1)."

"Küçük yaşlardan itibaren cimnastiğe gittim. Onun dışında yüzme ile ilgileniyorum. Kışın kayak ile ilgilenmeyi seviyorum. Yelken ve dalgıçlıkta bir dönem yaptım. Sporla baya bir içli dışlı oldum açıkçası. Fakat düşündüğümde cimnastik yapmış olmamın beni pilates ile tanıştırdı ̆̆ını düşünüyorum (K2)."

\section{Rekreatif Amaç Kategorisi}

Katılımcıların rekreatif amaç kategorisine ilişkin görüşleri, hobi olarak görme kodu ile belirtilmiştir. İlgili koda ait frekans değerinin 2 olduğu görülmektedir. Hobi olarak görme koduna ilişkin bir örnek görüş aşağıda verilmiştir.

"Daha önce lisanslı olarak bir spor ile ilgilenmedim ancak spor yapmayı seviyorum. Fitness, crossfit bir ara da yüzmeyi denedim. Ben aslında hobi olarak başladım. Hobi olarak yapacaksam da lisanslı neden olmasın diye düşündüm. Bu şekilde aslında yöneldim. Pilates benim son dakikaya eklediğim bir unsur. Bende hobi bu yüzdende (K3).

\section{Toplumsal Sebepler Kategorisi}

İlgili kategoride katılımcı görüşleri, popülarite $f(3)$, sosyal medya kullanımı $f(5)$ ve kadın kadına icra edilebilme $\mathrm{f}(1)$ olarak kodlanmıştır. Popülarite koduna yönelik katılımcılara ait örnek bir görüş aşağıda sunulmuştur.

“... şu anda pilates bence popüler olduğundan bir yönelim var. Kim nereye gidiyor pilatese, hadi bizde gidelim muhabbeti oluyor. Insanlar bu anlamda birbirlerinden etkileniyorlar. Bende buna ilgisiz kalamadim (K4)."

Sosyal medya kullanımı koduna yönelik katılımcılara ait bir görüş örneği aşağıda sunulmuştur.

"Herkes yediğini, içtiğini sosyal medyada paylaşlyor. Aynı şekilde pilates de bu grupta yer alıyor. Insanlar hareketleri düzgün yapıyor mu bu önemli değil. Onu görüntüledi mi yetiyor. Bu ne kadar beğeni getirir bunun peşinde. Aslında bunlar cezbediyor insanları. Bir başkası da bunu görerek bende gideyim diyor. Bu şekilde gelenlerde kendilerini sosyal medyada paylaşıyor. Döngü bu şekilde sürüp gidiyor. Fotoğraf ve video paylaşımı için gelen büyük bir kitle var. Böyle bir talep var instagramda paylaşmak için. Birçok arkadaşım var sosyal medyada paylaşım yapmak için başlayıp sonrasında bende yapabilirim düşüncesi ile eğitmen olan (K4)." 
Kadın kadına icra edilebilmesi koduna ilişkin katılımcılara ait bir görüş örneği aşağıda sunulmuştur.

“... ev hanımlart pilatese ilgi duyuyorlar. Ülkemizdeki sosyo ekonomik durum düşünüldüğ̈̈nde beyleri izin vermeyen kadınlar var. Onlarda bireysel hocalar ile çalışmayı daha çok seviyorlar. Bu sebepten dolayı da kadın kadına yapılma imkânı ile birlikte düşünüldügünde yönelme daha fazla oluyor. Pilateste kendilerini daha rahat hissediyorlar. Eğitmenler için düşünüldüğünde de bu böyle. Kendilerini rahat hissederek çallyorlar ve avantaj sağllyor (K3).”

\section{Fiziksel Sağlık Kategorisi}

Bu kategoride katılımc1 görüşleri, omurga ağrıları $f(3)$, bel ağrıları $f(3)$ ve boyun ağrıları $f(2)$ kodlamaları ile ifade edilmiştir. Omurga ağrıları koduna yönelik örnek bir görüş aşağıda verilmiştir.

“.. bir çok insan farkında değil ancak pilates să̆lık açısından çok önemli bir spor. Omurgasında problem olan insanların yaptı̆̆l da bir spor. Günlük yaşantısında masa başında oluşan bu tip rahatsızlıkları da gidermede önemli bir role sahip (K1)."

Bel ağrıları koduna yönelik katılımcılara ait bir görüş örneği aşağıda verilmiştir.

“... maalesef bizim halkımızda biliyorsunuz bel ağrıları sılklıkla karşılaşılan bir sorun. Birçok insanda bu ağrılarından kurtulabilmek için geliyor. Aslında sağlık yönü de dikkate değer bir spor (K4)."

Boyun ağrıları koduna yönelik katılımcılara ait görüş örneği aşağıda verilmiştir.

"Daha önce çalıştı̆̆ım kurumda bir arkadaşımın boyun ă̆rısı sorunu çektiğini öğrenmiştim. Kendisi bir doktorun tavsiyesi ile pilatese başlamıştı. Belli bir süre sonra konuştuğumuzda pilatesin çok fayda să̆ladı̆̆ını ve eskisi kadar ă̆rı hissetmediğini söylemişti (K4).’

Zihinsel Sağlık Kategorisi

Zihinsel sağlık kategorisinde katılımcı görüşleri, kendini iyi hissetme $\mathrm{f}(1)$ ve ruhsal doyum $\mathrm{f}(1)$ olarak kodlanmıştır. Kendini iyi hissetme koduna yönelik katılımcı görüşü aşağıda verilmiştir.

"Insanlar birçok farklı sebepten pilates sporuna başlamış olabilirler. Ben spor yaparken mutlu olduğum için kendimi iyi hissettiğim için bu işe yöneldim. Pilatese başlamamdaki etkenler düşünüldügünde en önemi sebep benim için buydu (K1)."

Ruhsal doyum koduna ilişkin katılımcılara ait görüş örneği aşağıda sunulmuş̧tur.

"Pilates başlı başına hem zihinsel hem de bedensel yani vücudumuzu rahatlatan bir spor olduğundan farklı bir önem taşıyor. Fiziksel açıdan tabi ki bir değişime uğruyorsun. Bunun yanında ruhsal ve zihinsel olarak da sizi rahatlatıyor. Dış dünyadan soyutlanıyorsunuz, kendinize iyi bir şey yaptı̆̆ınızı anlıyorsunuz (K4)."

Estetik Görünüm Kategorisi

İlgili kategoride katılımcı görüşleri, zayıflama $f(3)$, sıkılaşma $f(1)$, boy uzatma $f(1)$ ve vücut 
şekillendirme $\mathrm{f}(2)$ kodlamaları ile açıklanmaya çalışılmıştır. Zayıflama koduna ilişkin örnek katılımcı görüşü aşağıda verilmiştir.

“... insanlar hem bütün vücudu çalıştıracak bir unsur hem de yă̆ yakımını sağladı̆̆ için pilatesi seviyorlar, tercih ediyorlar. Denge kontrolünü sağlamada da gerçekten çok faydalı bir spor (K6).

Sıkılaşma koduna ilişkin katılımcı görüş örneği aşağıda verilmiştir.

"Pilates aslında çok yönlü bir spor dall. Bir taraftan fit bir görünüm elde edebilmek için vücudun tamamını çalıştırıyor, bir taraftan da zayıflama ve sıkılaşma aracı olarak görülüyor birçok kişi tarafindan (K10)."

Boy uzatma koduna ilişkin katılımcı görüş örneği aşağıda verilmiştir.

"Halk arasinda yata yata spor yapma olarak da anıliyor. Istemsizde olsa bir zaylflama durumu da oluyor. Bununla beraber boy uzattı̆̆ına inanan bir kitle de var. Bu yönden de aslında insanlar pilatese yönelebiliyorlar (K9).”

Vücut şekillendirme koduna yönelik örnek bir katılımcı görüşü aşağıda verilmiştir.

“... pilates fiziksel açıdan direk etkisini gösteren bir spor dalı. Farklı spor dalları ile aktif olarak ilgilenebilirsiniz ama bir yönü ile eksik kalabilirsiniz. Bu noktada da pilates devreye giriyor, vücudu şekle sokabiliyor. Aslına bakarsanız komplike bir görünüm sağlamada yardımcı oluyor (K9).",

\section{Tavsiye Kategorisi}

Tavsiye kategorisinde katılımcı görüşleri; patron yönlendirmesi $\mathrm{f}(1)$ ve komşu yönlendirmesi $\mathrm{f}(2)$ kodlamaları ile ifade edilmiştir. Patron yönlendirmesi konuna yönelik örnek bir katılımcı görüşü aşağıda verilmiştir.

"Bir spor salonunda diyetisyenlik yaptyorum. Zaten pilatese olan ilgim de burada başladı. Küçük yaşlardan itibaren spora meraklıyım açıkçası. Kendime bir şeyler katmak amacı ile düşünürken iş yerindeki patronum bana önerdi. Benim bu branşta başarll olabileceğimi düşündü ve bana tavsiye etti (K2)."

Komşu yönlendirmesi koduna yönelik örnek bir katılımcı görüşü aşağıda verilmiştir.

"Pilates genelde ev hanımlarının tercih ettiği bir spor. Örneğin, apartmanda vs. bir komşusunun gittiğini ve memnun kaldığını duyuyor. Buda etkili oluyor pilatese başlama konusunda (K8)."

Kolay Ulaşılabilirlik Kategorisi

$\mathrm{Bu}$ kategoride katılımcı görüşleri, evde gerçekleştirilebilme imkanı $\mathrm{f}(2)$ kodu ile belirtilmiştir. Örnek bir katılımcı görüşü aşağıda sunulmuştur.

"Bu kadar popüler olmasının sebeplerinden biri de sürdürülebilir olmasıdır diye düşünüyorum. Sicak veya soğuk herhangi bir hava koşulundan etkilenmeden yapllabiliyor, erişimin kolay oluşu da popülariteyi arttırıyor (K9)." 


\section{Maddi Beklentiler Kategorisi}

İlgili kategoride katılımcı görüşleri; yüksek maaş imkânı $f(5)$, mesleki yatırım $f(2)$ ve belge kiralayabilme imkanı f(1) kodları ile ifade edilmiştir. Yüksek maaş imkânı koduna örnek bir katılımcı görüşü aşağıda verilmiştir.

"Profesyonel olarak insanların yönelmesinin sebebi de parası çok iyi. Net bir şekilde bunu ifade edebilirim. Hatta en başa bunu rahatlıkla koyabilirim. Düşünelim ki aynı özel ders süresince pilates kadar para kazandıran bir branş bulmak çok zordur (K3).",

Mesleki yatırım kodu ile ilgili katılımcılara ait bir görüş örneği aşağıda sunulmuştur.

"Ben kendime bir şeyler katmak istiyorum. Cimnastikten dolayı benim ilgimi çekmişti ama daha sonraki süreçte bende spor salonunda çalıştı̆̆ımdan dolay işime yarayabilir diye düşündüm. Bu spora karşı ciddi bir talep var, ileride belki de kendi alanımla beraber bunu da yürütebilirim diye yola çıktım açıkçası (K2)."

Belge kiralayabilme kodu ile ilgili katılımcılara ait bir görüş örneği aşağıda verilmiştir.

"Belge kiralayanlar var. Antrenörlük belgesinden para kazananlar var. Belgesi var ama çalışmıyor sadece kiralıyor. Buda başka maddi bir durumu ortaya çıkarıyor (K5).”

Tablo 3. Katılımcıların alan ile ilgili belirtmiş oldukları sorunlar

\begin{tabular}{ccc}
\hline Kategoriler & Kodlar & Frekans \\
\hline Monopolleşme f(4) & -Eğitmen Belgesinin & 4 \\
& Verilmesinde Tek Bir Kurumun & \\
& Yetkili Oluşu & 5 \\
Antrenör Niteliği f(10) & -Eğitmen Sayısının Fazla Oluşu & 5 \\
& -Sportif Geçmişi Olmayan & \\
\hline Mekan (Stüidyo) Niteliği f(6) & Eğitmen Fazlalı̆̆ & 6 \\
\hline
\end{tabular}

Tablo 3 dikkate alındığında, katılımcıların alan ile ilgili ifade etmiş oldukları sorunlar 3 kategoride toplanmıştır. İlgili kategoriler; "Monopolleşme”, "Antrenör Niteliğì" ve "Mekân (Stüdyo) Niteliğgi” başlıkları ile belirtilmiştir. Kategorilerden toplamda 4 kod elde edilmiştir. Kategoriler dikkate alındığında; Monopolleşme kategorisinde, Eğitmen belgesinin verilmesinde tek bir kurumun yetkili oluşu kodu; Antrenör niteliği kategorisinde, Eğitmen sayısının fazla oluşu, Sportif geçmişi olmayan Eğitmen sayısının fazla oluşu kodları; Mekân (Stüdyo) Niteliği kategorisinde, Gereğinden fazla stüdyo kodu yer almaktadır.

Monopolleşme Kategorisi

Katılımcıların monopolleşme kategorisi ile ilgili görüşleri eğitmen belgesinin verilmesinde tek bir kurumun yetkili oluşu şeklinde kodlanmıştır. Bu koda ilişkin frekans değerinin 4 olduğu belirlenmiştir. İlgili koda yönelik örnek bir görüş aşağıda sunulmuştur.

"Denetim haricinde iyi eğitimler verilmesi gerekiyor. Tek bir yerin bu belgeyi vermemesi gerekiyor. Bu monopolleşme sağllyor ve fiyatın yükselmesine sebep oluyor. Buraya gelirken bilezik satıp gelen bir arkadaşım var. Birkaç kurum bu konuda yetki sahibi olmalı ki fiyat düşmeli. (K10)" 


\section{Antrenör Niteliği Kategorisi}

Katılımcıların antrenör niteliği kategorisine yönelik ifadeleri eğitmen sayısının fazla oluşu ve sportif geçmişi olmayan eğitmen fazlalığ 1 kodları ile açıklanmıştır. İlgili kodlara ilişkin frekans değerinin 10 olduğu tespit edilmiştir. Eğitmen sayısının fazla oluşu koduna yönelik örnek bir görüş aşağıda verilmiştir.

“... son yıllarda pilatese olan ilginin artması ister istemez ortadaki pasta payın da arttırdl. Maddi olanakların artması ile birlikte de birçok insan acaba bende yapabilir miyim düşüncesi ile eğitimlere katılmaya başladı ve belgeler aldı. Oysa ki bu kontrolsüz bir büyüme idi. (K6)"

Sportif geçmişi olmayan eğitmen fazlalığı koduna yönelik örnek bir katılımcı görüşü aşağıda sunulmuştur.

“Ülkemizde spora yönelik farkındalık düzeyi gün geçtikçe gelişiyor. İnsanlarda kendilerine uygun olan branşlar ile ilgilenmek istiyorlar doğal olarak. Bunun içinde pilates özellikle belli gruplar için daha cazip bir spor dall. Çünkü birçok kişiye göre sportif bir özgeçmiş durumu yok. Buda daha önce sporla hiç ilgili olmamış, üniversitede ilgili eğitimi almamış farklı bölümlerden mezun kişilerinde pilatesi meslek olarak yapabileceğini düşünmesine yol açtı. Sadece birkaç günlük eğitimler ile ezbere hareketler doğrultusunda bazen de insanlara yanlış açılarla hareketler yaptırarak, eğitmen olduklarını sanıyorlar. (K7)”,

Mekân (Stüdyo) Niteliği Kategorisi

Katılımcıların mekân (stüdyo) niteliği kategorisi ile ilgili görüşleri gereğinden fazla stüdyo şeklinde kodlanmıştır. Bu koda ilişkin frekans değerinin 6 olduğu belirlenmiştir. İlgili koda yönelik örnek bir görüş aşağıda sunulmuştur.

“...... maalesef denetimler istenilen seviyede değil. Ülkemizde pilates stüdyolarının niteliği ile ilgili de belirtilen bir yönetmelik yok. Bu durum hem stüdyo sayısının artmasına hem de stüdyoların niteliğinin istenilen seviyede olmamasina sebep oluyor. Bazen bir baklyorsunuz profesyonel özel bir kurum bünyesinde çok güzel olanaklar var, bazen de herhangi bir yerde apartman dairesinden bozma yerler var. Bu tabi ki hem pilatese olan saygll azaltıyor hem de niteliğin düşmesine sebebiyet veriyor. (K3)”,

\section{TARTIŞMA VE SONUÇ}

$\mathrm{Bu}$ araştırmada, pilates eğitmenlerinin bakış açısıyla branşa yönelim sebeplerinin incelenmesi ve alana ait sorunların belirlenmesi amaçlanmıştır. Literatür dikkate alındığında, pilatese yönelme sebeplerini ve alandaki sorunları ortaya koyan herhangi bir araştırmaya rastlanmamıştır. Bu sebeple araştırmadan elde edilecek bulguların, son yıllarda çok popüler bir hale gelen pilates branşına yönelmeyi sağlayan unsurların ortaya çıkarılmasına katkı sağlayacağı düşünülmektedir.

Analizler sonucunda pilates branşına yönelme sebepleri 9 kategori altında toplanmıştır. $\mathrm{Bu}$ kategoriler sırasıyla; "Spor geçmişi”, "Rekreatif amaç", "Toplumsal sebepler", Fiziksel 
sağlık", “Zihinsel sağlık”, Estetik görünüm”, “Tavsiye”, "Kolay ulaşılabilirlik” ve "Maddi beklentiler" başlıkları ile ortaya konulmuştur. İlgili kategorilerden toplamda 20 kod elde edilmiştir. Kategoriler dikkate alındığında; Spor geçmişi kategorisinde, "Farklı spor branşları ile ilgilenmiş olma" kodu; Rekreatif amaç kategorisinde, "Hobi olarak görme" kodu, Toplumsal sebepler kategorisinde, "Popülarite, Sosyal medya kullanımı, kadın kadına icra edilebilme" kodları, Fiziksel sağlık kategorisinde, "Omurga ağrıları, Bel ağrıları, Boyun ağrıları" kodları, Zihinsel sağlık kategorisinde, "Kendini iyi hissetme, Ruhsal doyum" kodları, Estetik görünüm kategorisinde, "Zayıflama, Sıkılaşma, Boy uzatma, Vücut şekillendirme" kodları, Tavsiye kategorisinde, "Patron yönlendirmesi, komşu yönlendirmesi" kodları, Kolay ulaşılabilirlik kategorisinde, "Evde gerçekleştirme imkanı" kodu, Maddi beklentiler kategorisinde ise, "Yüksek maaş imkanı, Mesleki yatırım ve Belge kiralayabilme imkanı" kodları yer almıştır.

Literatürde, araştırma sonuçları ile doğrudan ilişkilendirilebilecek bir çalışma olmasa da farkı branşlara veya genel anlamda spora yönelme sebeplerini inceleyen çalışmalar mevcuttur. Şimsek ve Gökdemir (2006) atletizm branşlarına yönelme sebeplerini inceledikleri çalışmasında; rekreatif amaçla yönelme, sporun kazanımlarını elde etme, sosyalleşebilme imkânı kazanma ve maddi geliri arttırma gibi nedenleri saptamıştır. Elger (2009) sporun, halk sağlığı ile ilgili öneminden bahsetmiş, uykusuzluk problemine çözüm sağladığını öne sürmüş ve bunun spora yönelmede etki unsuru olduğunu ifade etmiştir. Sunay ve Saracaloğlu (2003) esasen sağlıklı ve iyi bir fiziksel görünüme sahip olmak gibi etkenlerin önem taşıdığını vurgulamıştır. Kremer-Sadlik \& Kim (2007) akademik ve sosyal başarının arttırılması ile problem davranışların azalması amacıyla spora yönelmenin gerçekleştiğini vurgulamıştır. Şebin, Serarslan, Katkat, Tozoğlu ve Kızılet (2007) üniversite öğrencilerinin spora başlama sebepleri arasında; çevresel yönlendirmenin, yazılı ve görsel basının, başarılı sporcuların reklamının ve sağlıklı kalma arzusunun olduğunu ifade etmiştir. Grehaigne, Godbout \& Bouthier (2012) gözlem, eleştirel düşünme ve strateji geliştirmeyi sağlama amacının etkili olduğunu vurgulamıştır. Bununla beraber, çevresel etkenlerin ve kitle iletişim araçlarının da spora yönelmede etken olduğu bilinmektedir (Alibaz, Gündüz ve Şentuna, 2006; Kılcıgil, 1998). Belirtilen çalışmalar ile paralellik gösteren örnekler arttırabilir (Akgün, 2015; Arpa, 2014; Barber \& Sukhi, 1998; Kurtipek ve Sönmezoğlu, 2018). Dolayısıyla araştırma sonuçlarının literatür tarafından desteklendiği görülmektedir. Pilates branşına yönelme sebepleri arasında en dikkat çekici olan unsur sosyal medya kullanımının payıdır ( $\mathrm{f}=5$ ). Sosyal medyanın hedef kitleye ulaşmada doğrudan iletişim olanağı sunması sebebi ile önem taşıdığı ve bunun firsat unsuru olarak değerlendirilebileceği bilinmektedir (Hambrick, Simmons, Greenhalgh \& Greenweel, 2010; Wallece, Wilson \& Miloch, 2010). Bununla beraber, bireylerin bu platformda gerçekleştirilen paylaşımlardan etkilenerek pilatese başlamalarının çevre unsurunun yanı sıra farklı bir rekabet olgusundan kaynaklandığı düşünülmektedir. Ayrıca katılımcılar, fiziksel görünümü pozitif yönde geliştirmek ve sağlıklı olma arayışının da branşa yönelme nedenleri arasında önem taşıdığını ifade etmişlerdir. Maddi beklenti unsuru ise ayrı bir başlık altında incelenmesi gereken farklı bir konudur ( $\mathrm{f}=5$ ). Hemen hemen branşlara yönelme sebeplerinin incelendiği çalışmaların tamamında maddi beklenti unsuru ön plandadır. Bayraktar ve Sunay (2007) spora başlama noktasında maddi kazanım amacının ön planda olduğunu tespit etmiştir. Özbek ve Şanlı (2011) üniversitede 
öğrenim görmekte olan elit sporcuların karete branşına yönelmesinde maddi unsurların da pay sahibi olduğunu vurgulamıştır. Ölçücü, Özen ve Altınkök (2014) araştırmasında, maddi beklenti unsurunun spora başlama nedenleri arasında yer aldığını belirlemiştir. Ancak bu çalışmalarda yer alan katılımcıların çoğu lisanslı sporcudur. Pilates branşına ise spor geçmişi olmayan birçok insanın maddi beklenti düşüncesi ile yönelmesi nitelik sorununun kaynağını oluşturmaktadır.

Katılımcıların alan ile ilgili ifade etmiş oldukları sorunlar 3 kategoride toplanmıştır. İlgili kategoriler; "Monopolleşme", "Antrenör Niteliği”" ve "Mekân (Stüdyo) Niteliği’" başlıkları ile belirtilmiştir. Kategorilerden toplamda 4 kod elde edilmiştir. Kategoriler dikkate alındığında; Monopolleşme kategorisinde, "Eğitmen belgesinin verilmesinde tek bir kurumun yetkili oluşu" kodu; Antrenör niteliği kategorisinde, "Eğitmen sayısının fazla oluşu, Sportif geçmişi olmayan Eğitmen sayısının fazla oluşu" kodları; Mekân (Stüdyo) Niteliği kategorisinde, "Gereğinden fazla stüdyo" kodu yer almaktadır. Alana ait sorunlar dikkate alındığında, frekans değerleri $(\mathrm{f}=10)$ en önemli problemin antrenör niteliği ile ilgili olduğunu göstermektedir. Sportif geçmişe sahip antrenör sayısının az oluşu ve buna paradoks oluşturacak şekilde alandaki antrenör sayısının fazla oluşu en önemli problemler olarak dikkat çekmiştir. Kurtipek ve Güngör (2019) antrenörlerin/eğitmenlerin, sporun ve sporcunun gelişiminde rol oynayan önemli kilit taşları olduğunu ifade etmiştir. Bununla beraber antrenörler, sağlıklı yaşam amacıyla sportif aktivitelere katılım gösteren bireylerin gelişimini hedefleyen kişilerdir (Özbay Özen ve Özbay, 2018). Koçak (2019), sportif kariyere sahip antrenörlerin öz yeterlik düzeyinin bu kariyere sahip olmayan antrenörlere göre anlamlı düzeyde yüksek olduğunu saptamıştır. Feltz, Hepler, Roman \& Paiement (2009) de antrenörlerin öz yeterlik düzeyinin sporculuk deneyimi ile doğru orantılı olarak yükseldiğini belirlemiş̧ir. Bir başka dikkat çekici sorun ise stüdyo sayısındaki fazlalık olarak katılımcılar tarafından ifade edilmiştir $(\mathrm{f}=6)$. Bu durum aslında araştırmada bir başka sorun olarak belirtilen eğitmen sayısının fazla oluşu ile ilgilidir. Ne yazık ki merdiven altı diye tabir edilen stüdyo sayısının fazla olmasında antrenör sayısının da etkisi mevcuttur. Dolayısıyla da bu yerlerde çalışan kişilere güvenmenin yanlış hareket formlarından kaynaklı olarak ciddi sakatlıklara sebebiyet verebileceği düşünülmektedir.

Sonuç olarak, katılımcı görüşleri bireylerin pilatese yönelmelerinde fiziksel sağlık, estetik görünüm arayışı ve toplumsal sebeplerin etkili olduğunu göstermiştir. Pilates branşında eğitmenlik icra eden katılımcıların bu alanı tercih etmelerindeki en önemli etkenlerden birisinin ise yüksek maaş imkanının olduğu belirlenmiştir. Katılımcılar son yıllarda gittikçe talep gören bu alanı bir firsat olarak görmektedirler. Bununla beraber, sosyal medya kullanımı da dikkat çekici bir şekilde önem taşımaktadır. Bu noktada toplumun bu branşa olan bakış açısı ve ilgisi gerek eğitmenlerin gerekse de pilatese yeni başlayan kişilerin yönelim etkenlerinden biri olmuştur. Alana ait sorunlar arasında ise katılımc1 ifadeleri; eğitmen sayısının fazlalığını, eğitmenlerin büyük bir bölümünün sportif bir kariyere sahip olmamasını ve gereksiz stüdyo fazlalı̆ııı vurgulamışıtır. Bu noktadan hareketle; ilgili kurumlar tarafından "stüdyo" olarak tabir edilen yerlerin denetiminin sağlanması, eğitmenlik belgesinin alınabilmesi için belirli bir sportif geçmiş kriterinin konulması ve gerekli 
eğitimlerin belirli aralıklarla verilmesi alandaki insan kaynağı ve tesis niteliğin arttırılabilmesi amacıyla önerilmektedir.

Yayın Etiği: $\mathrm{Bu}$ çalışmanın hazırlanma ve yazım sürecinde "Yükseköğretim Kurumları Bilimsel Araştırma ve Yayın Etiği Yönergesi” kapsamında bilimsel, etik ve alıntı kurallarına uyulmuş olup; toplanan veriler üzerinde herhangi bir tahrifat yapılmamış ve bu çalışma herhangi başka bir akademik yayın ortamına değerlendirme için gönderilmemiştir.

\section{KAYNAKLAR}

Akgün, M. (2015). Türkiye’de buz hokeyi sporcularının branşa yönelme nedenleri ve katılım güdüsü. Yüksek Lisans Tezi, Gazi Üniversitesi Sağlık Bilimleri Enstitüsü, Ankara.

Alibaz, A., Gündüz, N., ve Şentuna, M. (2006). Türkiye'de üst düzey taekwondo, karate ve kick-boks sporcularının bu spor branşına yönelmelerine teşvik eden unsurlar, yapma nedenleri ve geleceğe yönelik beklentileri. SPORMETRE Beden Eğitimi ve Spor Bilimleri Dergisi, 4(3) 91-102. https://doi.org/10.1501/Sporm_0000000067.

Anderson, B.D., \& Spector, A. (2000). Introduction to Pilates-based rehabilitation. Orthopaedic Physical Therapy Clinics of North America, 9(3), 395-410.

Arpa, D.K. (2014). Ortaögretimdeki erkek sporcuların karate ve taekwondo branşına yönelme nedenleri ve beklentileri. Yüksek Lisans Tezi, Haliç Üniversitesi Sağlık Bilimleri Enstitüsü, İstanbul.

Barber, H., \& Sukhi, H. (1999). The influence of parent-coaches on participant motivation and competitive anxiety in youth sport participants. Journal of Sport Behavior, 22(4-5), 162-180.

Bassett, D.R, Schneider, P.L., \& Huntington, G.E. (2004). Physical activity in an Old Order Amish community, Med Sci Sports Exerc, 36, 79-85. https://doi.org/10.1249/01.MSS.0000106184.71258.32.

Bayraktar, B., ve Sunay, H. (2007). Türkiye'de elit bayan ve erkek voleybolcuların spora başlamasına etki eden unsurlar ve spordan beklentileri. SPORMETRE Beden Eğitimi ve Spor Bilimleri Dergisi, 5(2), 6372. https://doi.org/10.1501/Sporm_0000000077.

Boyce, R.W., Boone, E.L., Cioci, B.W., \& Lee, A.H. (2008). Physical activity, weight gain and occupational health among call centre employees. Occupational Medicine, 58(4), 238-244. https://doi.org/10.1093/occmed/kqm135.

Bryan, M., \& Hawson, S. (2003). The benefits of pilates exercise in orthopaedic rehabilitation. Techniques in Orthopaedics, 18(1), 126-129.

Bozkuş, T., Türkmen, M., Kul, M., Özkan, A., Öz, Ü., ve Cengiz, C. (2013). Beden Eğitimi ve Spor Yüksekokulu’nda öğrenim gören öğrencilerin fiziksel aktivite düzeyleri ile sağlıklı yaşam biçimi davranışlarının belirlenmesi ve ilişkilendirilmesi. International Journal of Science Culture and Sport, $1(3), 49-65$.

Cabbaroğlu, M. (2019). Sportif rekreasyon etkinliği olarak zumba ve pilatesin yaşam doyumu ve mutluluk üzerine etkisi (Muğla İli örneği). Yüksek Lisans Tezi, Muğla Sitk1 Koçman Üniversitesi Sosyal Bilimler Enstitüsü, Muğla.

Di Lorenzo, C.E. (2011). Pilates: What is it? Should it be be used in rehabilitation? Sports Health, 3(4), 352361. https://doi.org/10.1177/1941738111410285.

Egger, G.J., Vogels, N., \& Westerterp, K.R. (2001). Estimating historical changes in physical activity levels. Medical journal of Australia, 175(11-12), 635-636. https://doi.org/10.5694/j.13265377.2001.tb143758.x. 
Güngör, N. B., ve Esentürk, O. K. (2020). Eğitmenlerin bakış açısıyla pilatese yönelme sebepleri ve alandaki sorunlara ait görüşler. Ulusal Spor Bilimleri Dergisi, 4(1), 35-49.

Ekiz, D. (2009). Bilimsel araştırma yöntemleri: Yaklaşım, yöntem ve teknikler. Anı Yayıncılık.

Elger, B. S. (2009). Prison life: Television, sports, work, stress and insomnia in a remand prison. International Journal of Law and Psychiatry, 32(2), 7483. https://doi.org/10.1016/j.ijlp.2009.01.001.

Göz, E. (2020). Erken dönem parkinson hastalarında pilates ve elastik bantlama uygulamalarının denge ve postüral kontrol üzerine etkisi. Doktora Tezi, Dokuz Eylül Üniversitesi Sağlık Bilimleri Enstitüsü, İzmir.

Gréhaigne, J.F., Godbout, P., \& Bouthier, D. (2001). The teaching and learning of decision making in team sports. Quest, 53(1), 59-76. https://doi.org/10.1080/00336297.2001.10491730.

Hambrick, M., Simmons, J., Greenhalgh, G., \& Greenweel, C. (2010, June). Understanding athletes use of Twitter: A content analysis of athlete tweets. Paper presented in the North American Society for Sport Management Conference, Florida.

Feltz, D.L., Hepler, T.J., Roman, N., \& Paiement, C. (2009). Coaching efficacy and volunteer youth sport coaches. The Sport Psychologist, 23(1), 24-41. https://doi.org/10.1123/tsp.23.1.24.

Kalkan, B. (2019). Să̆llklı kadınlarda tüm vücut vibrasyon ĕgitimi ve pilates egzersizlerinin fiziksel uygunluk, yorgunluk ve fiziksel benlik algısı üzerindeki etkilerinin karşılaştırılması. Yüksek Lisans Tezi, Başkent Üniversitesi Sağlık Bilimleri Enstitüsü, Ankara.

Kayaoğlu, B. (2019). Yaşlılarda uygulanan pilates egzersizlerinin bilişsel ve fonksiyonel performas ile yaşam kalitesine etkisi. Yüksek Lisans Tezi. Uşak Üniversitesi Sağlık Bilimleri Enstitüsü, Uşak.

Keskin, K.C. (2018). Pilates egzersizlerinin kadınlarda vücut kompozisyonuna etkisi. Yüksek Lisans Tezi, Gazi Üniversitesi Sağlık Bilimleri Enstitüsü, Ankara.

Kılcıgil, E. (1998). Sosyal çevre-spor ilişkileri:(Teori ve elit sporculara ilişkin bir uygulama). Ankara: Bağırgan.

Kloubec, J.A. (2010). Pilates for improvement of muscle endurance, flexibility, balance, and posture. The Journal of Strength \& Conditioning Research, 24(3), 661-667. https://doi.org/10.1519/JSC.0b013e3181c277a6.

Koçak, Ç.V. (2019). Antrenör adaylarının antrenör öz yeterlik düzeylerinin incelenmesi. SPORMETRE Beden Eğitimi ve Spor Bilimleri Dergisi, 17(1), 55-62. https://doi.org/10.33689/spormetre.520507.

Kremer-Sadlik, T., \& Kim, J.L. (2007). Lessons from sports: Children's socialization to values through family interaction during sports activities. Discourse \& Society, 18(1), 35-52. https://doi.org/10.1177/0957926507069456.

Kurtipek, S., ve Güngör, N.B. (2019). Perception of trainers for the athlete. Turkish Journal of Sport and Exercise, 21(2), 379-385. https://doi.org/10.15314/tsed.519888.

Kurtipek, S., ve Sönmezoğlu, U. (2018). Determination of the perceptions of sports managers about sport concept: A metaphor analysis study. International Journal of Higher Education,7(4),17-25. https://doi.org/10.5430/ijhe.v7n4p17.

Merriam, S.B., \& Tisdell, E.J. (2015). Qualitative research: A guide to design and implementation. John Wiley \& Sons.

Mętel, S., Milert, A., \& Szczygieł, E. (2012). Pilates based exercise in muscle disbalances prevention and treatment of sports injuries. An International Perspective on Topics in Sports Medicine and Sports Injury, 381-402.

Miles, M.B., \& Huberman, A.M. (1994). Qualitative data analysis (2nd Ed.). United Kingdom: Sage Publication. 
Ölçücü, B., Özen, Ş., ve Altınkök, M. (2014). Spor eğitiminde Tokat ilinde voley takımlarında oynayan voleybolcuların voleybola başlama nedenleri ve beklentileri. Uluslararası Türk Eğitim Bilimleri Dergisi, 3, 57-70.

Özbek, O., ve Şanlı, E. (2011). Karete branşındaki üniversite elit sporcularının bu branşa yönelme nedenleri ve beklentileri. Niğde Üniversitesi Beden Ĕ̈itimi ve Spor Bilimleri Dergisi, 5(3), 203-214.

Özen, N.Ö., ve Özbay, A. Antrenörlerin mesleki imajına ilişsin nitel bir araştırma. Türkiye Spor Bilimleri Dergisi, 2(2), 74-81. https://doi.org/10.32706/tusbid.481509.

Ünal, E., ve Dizmek P. (2014). Romatoloji bilimi ve biyopsikososyal model: Bilişsel egzersiz terapi yaklaşımı (BETY). Ankara: Pelikan.

Patton, M.Q. (2014). Qualitative research \& evaluation methods: Integrating theory and practice. Sage publications.

Satcher, D., \& Lee R.P. (1996). Physical activity and health: A report of the surgeon general. 5th ed. U.S. Department of Health and Human Services Publication.

Segal, N.A., Hein, J., \& Basford, J.R. (2004). The effects of Pilates training on flexibility and body composition: an observational study. Archives of Physical Medicine and Rehabilitation, 85(12), 1977-1981. https://doi.org/10.1016/j.apmr.2004.01.036.

Sunay, H., ve Saracaloğlu, A. (2003). Türk sporcusunun spordan beklentileri ile spora yönelten unsurlar. SPORMETRE Beden Eğitimi ve Spor Bilimleri Dergisi, 1(1), 43-48. https://doi.org/10.1501/Sporm_0000000011.

Şebin, K., Serarslan, Z., Katkat, D., Tozoğlu, E., ve Kızılet, A. (2010). Spor yapan üniversite öğrencilerinin spora başlama ve spor yapma nedenlerine ilişkin görüşleri. Beden Eğitimi ve Spor Bilimleri Dergisi, 9(1), 43-63.

Şimsek, D., ve Gökdemir, K. (2006). Ortaöğretimde atletizm yapan sporcu öğrencilerin atletizm branşına yönelme nedenleri ve beklentileri. SPORMETRE Beden Ĕgitimi ve Spor Bilimleri Dergisi, 4(3), 83.90. https://doi.org/10.1501/Sporm_0000000066.

Wallace, L., Wilson, J., \& Miloch, K. (2010, June). Sporting facebook: A case study with the national football leauge. Paper presented in the North American Society for Sport Management Conference, Florida.

Wells, C., Kolt, G.S., \& Bialocerkowski, A. (2012, August). Defining pilates exercise: A systematic review. Complementary Therapies in Medicine, 253-262. https://doi.org/10.1016/j.ctim.2012.02.005.

Yıldırım, A., ve Şimşek, H. (2011). Sosyal bilimlerde araştırma yöntemleri. Ankara: Seçkin Yayınları.

Yıldırım, A., ve Şimşek, H. (2016). Sosyal bilimlerde nitel araştırma yöntemleri. Ankara: Seçkin Yayıncılık.

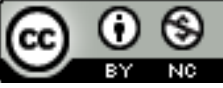

Bu eser Creative Commons Atıf-GayriTicari 4.0 Uluslararası Lisansı ile lisanslanmıştır. 